\title{
Prior appendectomy does not protect against subsequent development of malignant or borderline mucinous ovarian neoplasms
}

\section{Citation}

Elias, Kevin M., S. Intidhar Labidi-Galy, Allison F. Vitonis, Jason L. Hornick, Leona A. Doyle, Michelle S. Hirsch, Daniel W. Cramer, and Ronny Drapkin. 2014. “Prior Appendectomy Does Not Protect Against Subsequent Development of Malignant or Borderline Mucinous Ovarian Neoplasms." Gynecologic Oncology 132 (2) (February): 328-333. doi:10.1016/j.ygyno.2013.12.011.

\section{Published Version}

doi:10.1016/j.ygyno.2013.12.011

\section{Permanent link}

http://nrs.harvard.edu/urn-3:HUL.InstRepos:27331760

\section{Terms of Use}

This article was downloaded from Harvard University's DASH repository, and is made available under the terms and conditions applicable to Other Posted Material, as set forth at http:// nrs.harvard.edu/urn-3:HUL.InstRepos:dash.current.terms-of-use\#LAA

\section{Share Your Story}

The Harvard community has made this article openly available.

Please share how this access benefits you. Submit a story.

Accessibility 
Published in final edited form as:

Gynecol Oncol. 2014 February ; 132(2): 328-333. doi:10.1016/j.ygyno.2013.12.011.

\title{
Prior appendectomy does not protect against subsequent development of malignant or borderline mucinous ovarian neoplasms
}

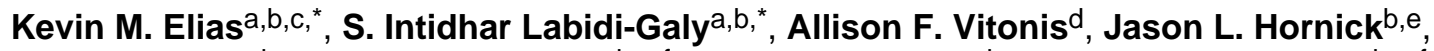 \\ Leona A. Doyle ${ }^{b, e}$, Michelle S. Hirsch ${ }^{b, e, f}$, Daniel W. Cramer ${ }^{d, g}$, and Ronny Drapkin ${ }^{a, b, e, f, h}$ \\ aDepartment of Medical Oncology, Dana-Farber Cancer Institute, Boston, MA \\ bHarvard Medical School, Boston, MA \\ 'Division of Gynecologic Oncology, Department of Obstetrics and Gynecology and Reproductive \\ Biology, Brigham and Women's Hospital, Boston, MA
}

dObstetrics and Gynecology Epidemiology Center, Department of Obstetrics and Gynecology and Reproductive Biology, Brigham and Women's Hospital, Boston, MA

eBrigham and Women's Hospital, Department of Pathology, Boston, MA

'Brigham and Women's Hospital, Division of Women's and Perinatal Pathology, Boston, MA

gDepartment of Epidemiology, Harvard School of Public Health, Boston, MA

\section{Abstract}

Background-Due to concern that mucinous malignant or borderline ovarian neoplasms (MON) may represent metastatic deposits from appendiceal primaries, gynecologic oncologists routinely perform appendectomy in these cases. However, a multidisciplinary critique of this practice is lacking.

Methods-The New England Case-Control study database was utilized to compare the effect of prior appendectomy against known risk factors for MON. Pathology and operative reports of local cases of MON were reviewed to estimate the frequency of microscopic mucinous lesions in the appendix. Protein expression patterns among mucinous ovarian, colorectal, and appendiceal cancers were compared by immunohistochemistry.

Results-From the New England Case-Control study, 287 cases of MON were compared against 2,339 age-matched controls. Prior appendectomy did not reduce the risk of MON (OR 1.28, 95\% CI $0.83-1.92, \mathrm{p}=0.23$ ), while prior tubal ligation, parity, and breastfeeding were each protective against MON. Active smoking (OR 2.04, 95\% CI 1.48-2.80, $p<0.001$ ) was associated with an increased risk of MON. Among 196 mucinous adnexal tumors, appendectomy did not reclassify any MON as appendiceal in origin. By immunohistochemistry, mucinous ovarian carcinomas

\footnotetext{
(C) 2013 Elsevier Inc. All rights reserved.

hAddress correspondences to: Ronny Drapkin, MD, PhD, Department of Medical Oncology, Dana-Farber Cancer Institute, JF215D,

450 Brookline Avenue, Boston, MA 02215, Tel: (617) 632-4380, ronny_drapkin@dfci.harvard.edu.

denotes equal author contribution

Publisher's Disclaimer: This is a PDF file of an unedited manuscript that has been accepted for publication. As a service to our customers we are providing this early version of the manuscript. The manuscript will undergo copyediting, typesetting, and review of the resulting proof before it is published in its final citable form. Please note that during the production process errors may be discovered which could affect the content, and all legal disclaimers that apply to the journal pertain.

Conflicts of Interest:

The authors report no relevant financial relationships or conflicts of interest pertaining to the present study.
} 
tended to be CK7+/CK20-/MUC2-/CDX2-, whereas mucinous colorectal and appendiceal adenocarcinomas were typically CK7-/CK20+/MUC2+/CDX2+, although with some overlap in immunophenotype. Additionally, PAX8 was positive in a subset of MOC and negative in all appendiceal carcinomas.

Conclusion-Prior appendectomy is not protective against development of malignant or borderline MON. Routine appendectomy during surgery for MON seldom reveals an unsuspected GI primary in early stage tumors but may aid in final diagnosis in advanced stage cases.

\section{Keywords}

mucinous ovarian neoplasms; epidemiology; risk factors; appendectomy

\section{Introduction}

Epithelial ovarian carcinomas (EOC) are the leading cause of death among gynecologic tumors [1]. EOC are histologically classified into four major subtypes: serous, clear cell, endometrioid, and mucinous [2,3]. Mucinous ovarian carcinomas have been the least studied of these, probably because of their relative rarity, comprising about 3\% or less of EOC [4]. Mucinous tumors can exist as both invasive and borderline tumors, here collectively referred to as mucinous ovarian neoplasms (MON). Although it has been argued that MON bear some relationship to the endocervix, the mucinous epithelium that characterizes MON more frequently resembles gastrointestinal (GI) epithelium [5]. Even when excluding cases of pseudomyxoma peritonei, which are now generally accepted to occur almost exclusively in association with appendiceal primaries, most pathologists still maintain that the diagnosis of primary MON requires consideration and exclusion of metastases from other GI carcinomas [6,7]. Indeed, the epidemiology, histology, and molecular biology of MON are routinely compared to GI mucinous carcinomas, in particular those arising in the colon [8]. Coupled with rare case reports of goblet cell carcinoids ("adenocarcinoid" tumors) presenting as isolated adnexal masses, these reports have advanced the notion that a significant proportion of MON are subsequently found to have arisen from an occult appendiceal or other GI primary, and therefore that the appendix should be routinely removed at the time of surgery for any malignant or borderline MON [9-12]. In addition, other authors have advocated routine appendectomy in all EOC cytoreductive surgeries regardless of histology to exclude isolated metastases from the ovary to the appendix [13-15]. As a result, routine appendectomy at the time of surgery for a suspected or confirmed (by frozen section) MON of malignant or borderline potential has become common.

In this study, we examine the relationship between malignant and borderline MON and mucinous appendiceal tumors. We test the idea that some seemingly isolated MON are actually derived from the appendix by using a large regional case-control study to compare the effect of prior appendectomy against established risk factors for EOC. We then report our recent clinical experience with regards to the issue of occult appendiceal primaries at the time of surgery for suspected malignant or borderline MON and microscopic metastases from MON to the appendix. Finally, we compare the immunohistochemical (IHC) pattern of mucinous ovarian carcinomas (MOC) to mucinous appendiceal and colorectal carcinomas to test the ability of pathologists to discriminate among these clinical entities.

\section{Materials and Methods}

\section{New England Case-Control Study}

Data derived from four phases of a case-control study of ovarian cancer, the New England Case-Control (NECC) study, were used [16,17]. Cases were enrolled from 7/1984-9/1987 
(NECC2), 5/1992 - 3/1997 (NECC3), 8/1998 - 4/2003 (NECC4), and 10/2003 - 11/2008 (NECC5). Data from an earlier phase between 1978 and 1981 (NECC1) were no longer available electronically and not included. NECC 2 identified ovarian cancer cases from ten hospitals in Boston; NECC3, 4, and 5 used statewide cancer registries and tumor boards to identify cases diagnosed in Eastern Massachusetts and the State of New Hampshire. The four phases enrolled 2,475 cases including 2,274 with epithelial ovarian cancers, of which 287 were mucinous. Controls for NECC 3 were identified by random-digit dialing supplemented with residents' lists for older controls. About $10 \%$ of households dialed had an eligible control and of these, 421 (72\%) agreed to participate. All controls for NECC2, 4, and 5 were identified through town residents' lists in Massachusetts and Driver License Registries in New Hampshire. Of 5,151 potential controls identified through town books in all phases, 1,671 were ineligible due to bilateral oophorectomy, 1,562 declined participation, and 1,918 were enrolled. In total, 2,339 controls were enrolled. This study is approved by the Brigham and Women's Hospital and Dartmouth Medical Center Institutional Review Boards.

\section{Chart review}

The medical charts of 106 patients from the NECC study population were available for review by virtue of being operated on at either Brigham and Women's Hospital or Massachusetts General Hospital. These were combined with an additional 64 patients operated on at Brigham and Women's from 2006-2011 not enrolled in NECC. Operative reports and pathology reports from these cases were read to determine the frequency of appendectomy at the time of surgery and the incidence of microsopic metastases to the appendix from the ovary. In addition, the medical charts of an additional 26 patients operated on by the gynecologic oncology service at Brigham and Women's Hospital for an adnexal mass with the subsequent finding of a GI primary cancer were assessed by a member of the gynecologic oncology division (KME) for the frequency of a microscopic GI primary that would have been diagnosed only by routine appendectomy and not by examination of the other pathologic specimens obtained via oophorectomy or other cytoreductive procedures. Chart review was approved by the Partners Healthcare Institutional Review Board.

\section{Statistical methods}

For the case control study, continuous variables were categorized based on quartiles of the control distributions. Subjects with missing exposures were excluded on an exposurespecific basis. Unconditional logistic regression models were used to assess the associations between exposures and MON. All models were adjusted for the matching factors (age, study site, study phase), as well as parity, breastfeeding, OC use, genital talc exposure, Jewish ethnicity, and tubal ligation. All analyses were performed with SAS (SAS Institute, Cary, NC). Immunohistochemical staining results were compared using Fisher's exact test (GraphPad Software, La Jolla, CA).

\section{Pathology samples}

A total of 65 cases of mucinous tumors were selected from the surgical pathology files of the Brigham and Women's Hospital including 21 mucinous ovarian carcinomas, 18 mucinous colon carcinomas (MCCs), and 26 mucinous appendiceal carcinomas (MACs). Sites of origin of all tumors were known before this study on the basis of clinical and radiologic information in addition to surgical specimen examination. The tissues had been routinely fixed in $10 \%$ neutral formalin and embedded in paraffin. At least one paraffin tissue block with tumor was selected from each case by a pathologist with expert training in gynecologic or gastrointestinal pathology (MSH or JLH and LAD, respectively). 


\section{Immunohistochemistry}

Commercially available antibodies to keratin 7 (CK7), keratin 20 (CK20), CDX-2, $\beta$ catenin, MUC-2, SMAD4, and PAX-8 were evaluated in all cases (Table S1). The sections were deparaffinized and rehydrated in graded alcohol. The sections were then brought to an automated stainer (DAKO Corporation,Carpinteria, CA). For epitope retrieval, the sections for MUC-2, CDX-2, PAX-8, $\beta$-catenin, and SMAD4 were subjected to Dako TRS Retrieval buffer, and the sections for CK20 and CK7 were enzyme digested. DAKO Envision +polymer detection methods were used. Appropriate positive and negative (without primary antibodies) controls were used simultaneously for each antibody. The scoring was semiquantitative as follows: $0,1+(1-5 \%), 2+(6-25 \%), 3+(26-50 \%)$, or $4+(>50 \%)$ based on cytoplasmic (CK7, CK20), membranous (MUC2), or nuclear (CDX-2, PAX8) positivity; only cases $>2+$ were scored as "positive." SMAD4 was considered positive if there was complete loss of nuclear and cytoplasmic staining. $\beta$-catenin was evaluated for a membranous (negative) or nuclear (positive) staining pattern.

\section{Results}

\section{Risk factors for mucinous ovarian neoplasms}

The New England Case-Control (NECC) study included 287 cases of MON and 2,339 agematched controls (Table 1). Among the MON, 169 cases were borderline tumors and 118 cases were invasive adenocarcinomas. There was no protective effect against MON conferred by appendectomy either overall (OR 1.28, 95\% CI $0.83-1.92, \mathrm{p}=0.23)$ or in the borderline (OR 1.41, 95\% CI 0.83-2.39, $\mathrm{p}=0.2$ ) or invasive adenocarcinoma (OR 1.12, 95\% CI $0.63-1.99, \mathrm{p}=0.69$ ) patient subsets (Tables $1, \mathrm{~S} 2$, and $\mathrm{S} 3$ ). Among the invasive carcinomas, there was no relationship between prior appendectomy and stage (Table S4). In contrast, prior tubal ligation (OR $0.65,95 \%$ CI $0.43-0.99, \mathrm{p}=0.05$ ), parity (OR $0.56,95 \%$ CI $0.40-0.79, \mathrm{p}=0.0009)$, and breastfeeding $(\mathrm{OR} 0.62,95 \%$ CI $0.47-0.83, \mathrm{p}=0.002)$ were each associated with a lower risk of MON. Compared to controls, MON cases were more likely to be current smokers (OR 2.04, 95\% CI 1.48-2.80, p<0.0001). A dose-dependent effect was seen with smoking (p-trend $<0.0001$ ), with the highest risk of MON occurring among women with a smoking history of more than 28 pack years (OR 2.68, 95\% CI 1.85-3.89, $\mathrm{p}<0.0001$ ). In contrast to other types of epithelial ovarian neoplasm, there was no association between MON and either a personal or family history of breast cancer [18]. Similarly, the protective effect of oral contraceptive use against MON only reached borderline significance ( $\mathrm{p}$-trend=0.06).

\section{Frequency of microscopic appendiceal GI tumors as isolated ovarian neoplasms}

All gynecologic oncology cases from 2006-2011 were reviewed, and 26 cases were surgeries for a pelvic mass subsequently identified to be a mucinous GI tumor metastatic to the ovary (Table 2). Among these, 8 were appendiceal tumors, 8 were colorectal tumors, 8 were of unclear GI origin, and 1 tumor each was of gastric or small bowel origin. All 26 cases presented with widely metastatic disease. Among these, only 1 tumor (3.8\%) was felt to have potentially arisen from a microscopic GI primary. In that case, the appendix had been removed seven years prior. Both on the original pathology and on review seven years later, a mucinous cystadenoma was seen in the appendix but no evidence of carcinoma. Even so, the patient's widely metastatic tumor was histologically consistent with an appendiceal primary, not a MON. Additionally, among the 26 cases there was one case of an incidental carcinoid tumor, not related to the patient's colorectal primary, and one case of appendiceal cancer where the appendix was fused to the ovary and thus not grossly identifiable at the time of surgery. There were 9 cases (34.6\%) classified as GI primaries in part due to signet-ring cell morphology in either the adnexal lesion or metastatic implants from elsewhere in the pelvis. 


\section{Frequency of microscopic metastases from MON to the appendix}

As another possible indication to remove the appendix at the time of surgery for MON would be to exclude unsuspected metastases from the ovary to the appendix, we also evaluated the frequency of microscopic, isolated appendiceal metastases from the ovary (Table 3). 170 cases of MON were reviewed, 106 from the NECC study population and 64 additional patients operated on at Brigham and Women's Hospital but not enrolled in the NECC study. 91 cases involved borderline mucinous tumors and 79 cases involved invasive mucinous carcinomas. Pathology reports for the appendix were available in 72 (42.4\%) cases. Among the appendectomy specimens, there was 1 subcentimeter carcinoid tumor and 3 cases of superficial metastases from the ovarian lesion to the appendix, all in the setting of gross metastatic disease. All other appendectomy specimens were benign. No isolated microscopic metastases to the appendix or microscopic mucinous appendiceal adenocarcinomas in appendectomy specimens were observed.

\section{Immunophenotypes of mucinous ovarian and GI carcinomas}

Even though mucinous appendiceal and MON appear to be distinct by epidemiological and clinical criteria, there remains the concern that an appendiceal primary could be missed if the appendix is not sufficiently evaluated at the time of surgery. To address this issue, we tested the ability of several common immunohistochemical stains to discriminate among mucinous appendiceal, colorectal, and ovarian carcinomas (Figure 1 and Table 4). We obtained samples from 21 mucinous ovarian carcinomas (MOC), 18 mucinous colorectal cancers, and 26 mucinous appendiceal cancers and looked specifically to the most discriminating markers previously reported [19]. All MOC $(21 / 21,100 \%)$ were diffusely positive for CK7, whereas mucinous colorectal cancers $(3 / 18,17 \%)$ and mucinous appendiceal cancers $(8 / 26,31 \%)$ were more likely to be negative or demonstrate only focal expression of CK7 ( $<<0.0001$ for both tumor types). Some MOC $(9 / 21,43 \%)$ were focally or multifocally positive for CK20 while all mucinous colorectal cancers $(18 / 18,100 \%)$ and most mucinous appendiceal cancers $(25 / 26,96 \%)$ were diffusely positive $(\mathrm{p}<0.0001$ for both). Similarly, some MOC $(8 / 21,38 \%)$ stained focally for MUC2 whereas all mucinous colorectal cancers $(18 / 18,100 \%)$ and most mucinous appendiceal cancers $(25 / 26,96 \%)$ were diffusely positive ( $\mathrm{p}<0.0001$ for both). Likewise, some MOC were positive for CDX2 $(6 / 21,29 \%)$, but all mucinous colorectal cancers and most mucinous appendiceal cancers were diffusely positive $(18 / 18,100 \%$ and $25 / 2696 \%$, respectively, $\mathrm{p}<0.0001$ for both). None of the MOC showed nuclear staining for $\beta$-catenin compared to $9 / 18(50 \%)$ of mucinous colorectal cancers $(\mathrm{p}=0.0018)$. Although only a few MOC $(5 / 21,24 \%)$ stained for PAX8, no PAX8 staining was observed in either appendiceal or colorectal specimens $(p=0.0133$ and $p=0.0502$, respectively). Loss of SMAD4 staining was rare among all tumor types.

\section{Discussion}

In this study, we systematically examined the relationship between malignant and borderline mucinous ovarian neoplasms (MON) and mucinous adenocarcinomas of the appendix using epidemiological, clinical, and immunohistochemical means. This investigation stemmed from the longstanding tradition of removing the appendix at the time of surgery for suspected mucinous ovarian neoplasms based on the assumption that some unknown proportion of apparent MON are due to an occult appendiceal lesion. While our study is based on histological specimens removed at the time of surgery after a final pathological diagnosis had been determined, our findings agree with the findings of three other recent studies, which together identified no cases of an occult appendiceal mucinous adenocarcinoma in a grossly normal appendix out of 476 appendectomies performed at the time of surgery for a mucinous ovarian neoplasm [20-22]. Even so, as indicated by the fact 
that $42.4 \%$ of patients in our study had an appendectomy at the time of surgery, the procedure is still frequently performed.

While the previous studies also used cases series to explore the relationship between MON and the appendix, this is the first study to our knowledge to look for an epidemiologic connection between the two. Were MON mostly or even frequently derived from the appendix, one would expect that having had a prior appendectomy would offer some protection against the development of MON. In this study we found no such association. In addition, we found no protective effect from hysterectomy either, arguing against the uterus or endocervix as other putative sites of MON precursors [23]. Instead, factors known to be protective against the development of other forms of EOC, namely parity, tubal ligation, and breastfeeding, appear to be the most protective against MON. We also confirmed previous reports which have shown a relationship between smoking and MON [24-26].

Despite the epidemiologic evidence distinguishing MON from mucinous appendiceal adenocarcinomas, routine appendectomy has been the practice at our institution as in many other centers. In this study, we show that the frequency of an occult appendiceal tumor masking as an overt MON is extremely rare. Similarly, cases of microscopic metastases from a MON to the appendix were also uncommon. Removal of the appendix is warranted when there is gross involvement of the organ clinically, or when widely metastatic disease makes the organ of origin uncertain. It is also essential in cases of pseudomyxoma peritonei as these are almost always of appendiceal origin. While it seems unlikely that removal of a grossly normal appearing appendix will reveal a microscopic focus of an unsuspected mucinous appendiceal primary metastatic to what otherwise appears to be a Stage IA mucinous ovarian neoplasm or borderline tumor, thorough evaluation of the appendix at the time of surgery is still recommended.

In cases where the appendix was not removed at the time of surgery for suspected MON, immunohistochemical staining may help distinguish ovarian from appendiceal or colorectal carcinomas. Mucinous ovarian carcinomas tend to be CK7+/CK20-/MUC2-/CDX2-, with variable expression of PAX8. In contrast, mucinous colorectal cancers and mucinous appendiceal cancers usually feature a CK7-/CK20+/MUC2+/CDX2+/PAX8-

immunophenotype, with nuclear staining for $\beta$-catenin potentially more common among colorectal adenocarcinomas. Even so, no single marker should be relied upon to make the diagnosis due to the overlap in staining patterns, although the presence of signet-ring cell morphology favors a primary GI rather than ovarian neoplasm [27]. In addition, molecular studies have shown that cases of pseudomyxoma peritonei are almost never of ovarian origin [28-31].

Finally, while malignant and borderline MON seem to be distinct from appendiceal tumors, MON do display several characteristics that distinguish them from other EOC. Unlike other EOC, there appears to be no association between MON and either a personal or family history of breast cancer and only a weak relationship between MON and oral contraceptive use. Moreover, PAX8 staining, which characterizes most Müllerian malignancies, is less common among MON. These findings suggest that MON has a unique pathogenesis. Future studies looking at MON precursors may help clarify whether they have a unique origin.

\section{Supplementary Material}

Refer to Web version on PubMed Central for supplementary material. 


\section{Acknowledgments}

This work was supported by the NIH/National Cancer Institute (NCI) SPORE in Ovarian Cancer (P50-CA105009) and R21 (CA-156021); the Honorable Tina Brozman "Tina's wish" Foundation; the Dr. Miriam and Sheldon G. Adelson Medical Research Foundation (AMRF), Susan Smith Center (SSC) at Dana Farber Cancer Institute, The Robert and Deborah First Fund, The Gamel Family Fund, the Mary Kay Foundation, and the Sandy Rollman Ovarian Cancer Foundation. SILG is a recipient of grants from Arthur Sachs/Fulbright/Harvard, La Fondation Philippe and La Fondation de France - "Recherche clinique en cancérologie - Aide à la mobilité des chercheurs".

\section{References}

1. Jemal A, Siegel R, Ward E, et al. Cancer statistics 2008. CA Cancer J Clin. 2008; 58:71-96. [PubMed: 18287387]

2. Vaughan S, Coward JI, Bast RC Jr, et al. Rethinking ovarian cancer: recommendations for improving outcomes. Nat Rev Cancer. 2011; 11:719-725. [PubMed: 21941283]

3. Karst AM, Drapkin R. Ovarian cancer pathogenesis: a model in evolution. J Oncol. 2010; 2010:932371. [PubMed: 19746182]

4. Seidman JD, Kurman RJ, Ronnett BM. Primary and metastatic mucinous adenocarcinomas in the ovaries: incidence in routine practice with a new approach to improve intraoperative diagnosis. Am J Surg Pathol. 2003; 7:985-993. [PubMed: 12826891]

5. Kurman RJ, Shih Ie M. Molecular pathogenesis and extraovarian origin of epithelial ovarian cancer —shifting the paradigm. Hum Pathol. 2011; 42:918-931. [PubMed: 21683865]

6. O'Connell JT, Hacker CM, Barsky SH. MUC2 is a molecular marker for pseudomyxoma peritonei. Mod Pathol. 2002; 15:958-972. [PubMed: 12218214]

7. Hart WR. Mucinous tumors of the ovary: a review. Int J Gynecol Pathol. 2005; 24:4-25. [PubMed: 15626914]

8. Kelemen LE, Kobel M. Mucinous carcinomas of the ovary and colorectum: different organ, same dilemma. Lancet Oncol. 2011; 12:1071-1080. [PubMed: 21616717]

9. Thomas R, Barnhill D, Worsham F, Hoskins W. Krukenberg tumor of the ovary from an occult appendiceal primary: case report and literature review. Obstet Gynecol. 1985; 65:95S-98S. [PubMed: 2983277]

10. Mandai M, Konishi I, Tsuruta Y, Suginami N, Kusakari T, Iwasaki I, Fujii S. Krukenberg tumor from an occult appendiceal adenocarcinoid: a case report and review of the literature. Eur J Obstet Gynecol Reprod Biol. 2001; 97:90-95. [PubMed: 11435017]

11. Hood IC, Jones BA, Watts JC. Mucinous carcinoid tumor of the appendix presenting as bilateral ovarian tumors. Arch Pathol Lab Med. 1986; 110:336-340. [PubMed: 3006629]

12. Cadron I, Leunen K, Van Gorp T, Amant F, Neven P, Vergote I. Management of borderline ovarian neoplasms. J Clin Oncol. 2007; 25:2928-2937. [PubMed: 17617524]

13. Ayhan A, Gultekin M, Taskiran C, Salman MC, Celik NY, Yuce K, Usubutun A, Kucukali T. Routine appendectomy in epithelial ovarian carcinoma: is it necessary? Obstet Gynecol. 2005; 105:719-724. [PubMed: 15802396]

14. Rose PG, Abdul-Karim FW. Isolated appendiceal metastasis in early ovarian carcinoma. J Surg Oncol. 1997; 64:246-247. [PubMed: 9121158]

15. Timofeev J, Galgano MT, Stoler MH, Lachance JA, Modesitt SC, Jazaeri AA. Appendiceal pathology at the time of oophorectomy for ovarian neoplasms. Obstet Gynecol. 2010; 116:13481353. [PubMed: 21099601]

16. Harlow BL, Cramer DW, Bell DA, Welch WR. Perineal exposure to talc and ovarian cancer risk. Obstet Gynecol. 1992; 80:19-26. [PubMed: 1603491]

17. Vitonis AF, Titus-Ernstoff L, Cramer DW. Assessing ovarian cancer risk when considering elective oophorectomy at the time of hysterectomy. Obstet Gynecol. 2011; 117:1042-1050. [PubMed: 21471855]

18. Lee JS, John EM, McGuire V, Felberg A, Ostrow KL, DiCioccio RA, Li FP, Miron A, West DW, Whittemore AS. Breast and ovarian cancer in relatives of cancer patients, with and without BRCA mutations. Cancer Epidemiol Biomarkers Prev. 2006; 15:359-363. [PubMed: 16492929] 
19. Chu PG, Chung L, Weiss LM, Lau SK. Determining the site of origin of mucinous adenocarcinoma: an immunohistochemical study of 175 cases. Am J Surg Pathol. 2011; 35:1830 1836. [PubMed: 21881489]

20. Guvenal T, Dursun P, Hasdemir PS, Hanhan M, Guven S, Yetimalar H, et al. Effect of surgical staging on 539 patients with borderline ovarian tumors: A Turkish Gynecologic Oncology Group study. Gynecol Oncol. 2013 pii: S0090-8258(13)01123-2 [Epub ahead of print].

21. Feigenberg T, Covens A, Ghorab Z, Ismiil N, Dubé V, Saad RS, Khalifa MA, Nofech-Mozes S. Is routine appendectomy at the time of primary surgery for mucinous ovarian neoplasms beneficial? Int J Gynecol Cancer. 2013; 23:1205-1209. [PubMed: 23835504]

22. Lin JE, Seo S, Kushner DM, Rose SL. The role of appendectomy for mucinous ovarian neoplasms. Am J Obstet Gynecol. 2013; 208:46.e1-46.e4. [PubMed: 23117124]

23. Elishaev E, Gilks CB, Miller D, Srodon M, Kurman RJ, Ronnett BM. Synchronous and metachronous endocervical and ovarian neoplasms: evidence supporting interpretation of theovarian neoplasms as metastatic endocervical adenocarcinomas simulating primary ovarian surface epithelialneoplasms. Am J Surg Path. 2005; 29:281-294. [PubMed: 15725796]

24. Jordan SJ, Green AC, Whiteman DC, Webb PM. Australian Ovarian Cancer Study Group. Risk factors for benign, borderline and invasive mucinous ovarian tumors: epidemiological evidence of a neoplastic continuum? Gynecol Oncol. 2007; 107:223-230. [PubMed: 17662378]

25. Gates MA, Rosner BA, Hecht JL, Tworoger SS. Risk factors for epithelial ovarian cancer by histologic subtype. Am J Epidemiol. 2010; 171:45-53. [PubMed: 19910378]

26. Collaborative Group on Epidemiological Studies of Ovarian Cancer. Ovarian cancer and smoking: individual participant meta-analysis including 28,114 women with ovarian cancerfrom 51 epidemiological studies. Lancet Oncol. 2012; 13:946-956. [PubMed: 22863523]

27. Young RH. From krukenberg to today: the ever present problems posed by metastatic tumors in the ovary: part I. Historical perspective, general principles, mucinous tumors including the krukenberg tumor. Adv Anat Pathol. 2006; 13:205-207. [PubMed: 16998315]

28. Feltmate CM, Lee KR, Johnson M, Schorge JO, Wong KK, Hao K, Welch WR, Bell DA, Berkowitz RS, Mok SC. Whole-genome allelotyping identified distinct loss-of-heterozygosity patterns in mucinous ovarian and appendiceal carcinomas. Clin Caner Res. 2005; 11:7651-7657.

29. Chuagui RF, Zhuang Z, Emmert-Buck MR, Bryant BR, Nogales F, Tavassoli FA, Merino MJ. Genetic analysis of synchronous mucinous tumors of the ovary and appendix. Hum Pathol. 1996; 27:165-171. [PubMed: 8617458]

30. Cuatrecasas M, Matias-Guiu X, Prat J. Synchronous mucinous tumors of the appendix and the ovary associated with pseudomyxoma peritonei. A clinicopathologic study of six cases with comparative analysis of c-Ki-ras mutations. Am J Surg Path. 1996; 20:739-746. [PubMed: 8651354]

31. Szych C, Staebler A, Connolly DC, Wu R, Cho KR, Ronnett BM. Molecular genetic evidence supporting the clonality and appendiceal origin of Pseudomyxoma peritonei in women. Am J Surg Path. 1999; 154:1849-1855. 


\section{Research Highlights}

- Prior appendectomy is not protective against subsequent mucinous ovarian neoplasms.

- Occult mucinous tumors in the appendix at the time of surgery are rare events.

- Immunohistochemistry may help resolve the origin of some mucinous neoplasms 


\section{$H \& E$}

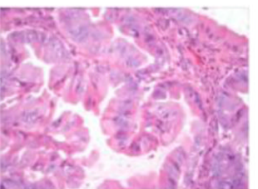

MCC
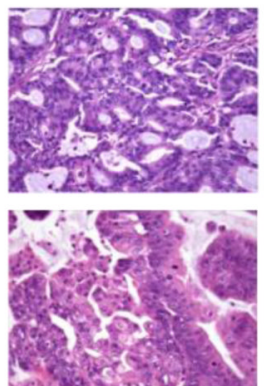

CK7
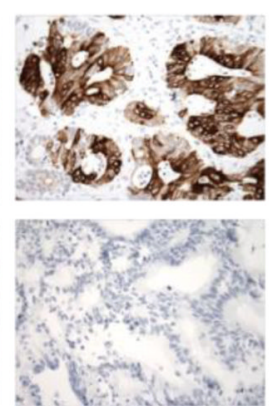

MAC

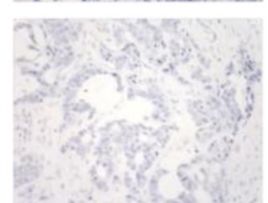

CK20
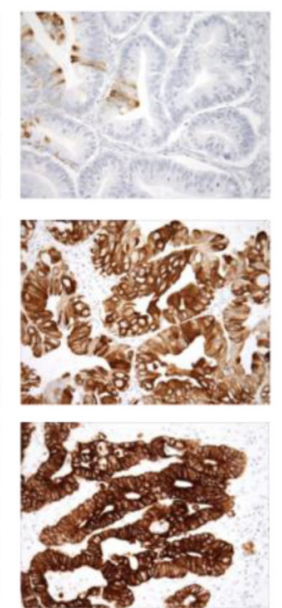

CDX2
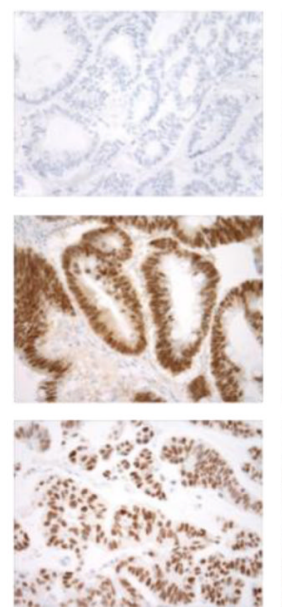

MUC2
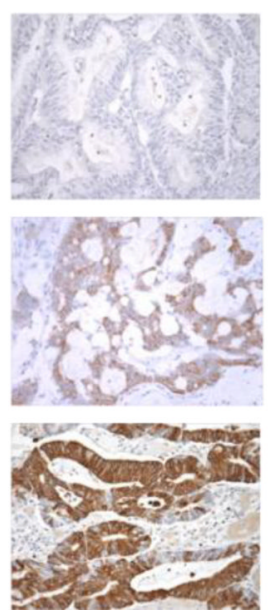

PAX8
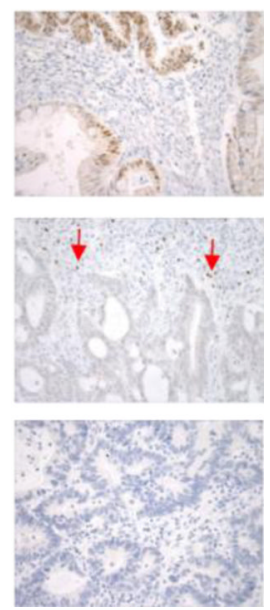

Figure 1. Morphologic and Immunohistochemical features of Mucinous Neoplasms (400x) Mucinous ovarian carcinomas (MOC), mucinous colorectal carcinomas (MCC), and mucinous appendiceal tumors/carcinomas (MAC) were evaluated with a hematoxylin and eosin stain (H\&E), and immunostained for CK7, CK20, CDX2, MUC2, PAX8, BetaCatenin (not shown), and Smad4 (not shown). Varying degrees of mucinous differentiation were present by $\mathrm{H} \& \mathrm{E}$ in the ovarian, colorectal, and appendiceal carcinomas.

Immunohistochemical analysis demonstrated that MOCs were typically positive for CK7 and negative for CK20, although rare cells were occasionally positive for CK20, as shown. CDX2 and MUC2 were typically negative in MOCs. PAX8 was weakly positive in a small subset ( 24\%) of MOCs. The majority of MCCs were diffusely positive for CK20, CDX2, and MUC2 and negative for CK7 and PAX8 (red arrows mark immunoreactive lymphocytes which act as an internal positive control). MACs demonstrated a similar immunoprofile compared to MCCs, with the exception of nuclear staining for $\beta$-catenin. 
Table 1

Risk factors for mucinous ovarian neoplasms from the New England Case-Control study

\begin{tabular}{|c|c|c|c|c|}
\hline & $\begin{array}{c}\text { Controls } \\
\mathbf{n}=\mathbf{2 3 3 9} \\
\mathbf{N}(\%)\end{array}$ & $\begin{array}{l}\text { Cases } \\
\mathbf{n}=\mathbf{2 8 7} \\
\mathrm{N}(\%)\end{array}$ & $\begin{array}{c}\text { Adjusted }^{*} \\
\text { OR (95\% CI) }\end{array}$ & p-value \\
\hline \multicolumn{5}{|l|}{ Age } \\
\hline$<44$ & $603(25.8)$ & $128(44.6)$ & -- & -- \\
\hline $44-53$ & $613(26.2)$ & $69(24.0)$ & -- & -- \\
\hline $54-62$ & $561(24.0)$ & $46(16.0)$ & -- & -- \\
\hline$>62$ & $562(24.0)$ & 44 (15.3) & -- & -- \\
\hline \multicolumn{5}{|l|}{ Smoking } \\
\hline Never & 1108 (47.4) & $123(42.9)$ & 1.00 (referent) & \\
\hline Former & 873 (37.3) & $79(27.5)$ & $0.95(0.70,1.30)$ & 0.77 \\
\hline Current & $358(15.3)$ & 85 (29.6) & $2.04(1.48,2.80)$ & $<0.0001$ \\
\hline \multicolumn{5}{|l|}{ Pack years } \\
\hline Never smoked & 1108 (47.7) & $123(43.3)$ & 1.00 (referent) & \\
\hline$<3$ & 307 (13.2) & $25(8.8)$ & $0.70(0.44,1.11)$ & 0.13 \\
\hline $3.1-12.4$ & $302(13.0)$ & 34 (12.0) & $1.01(0.67,1.52)$ & 0.97 \\
\hline $12.5-27.9$ & 299 (12.9) & $41(14.4)$ & $1.44(0.97,2.14)$ & 0.07 \\
\hline$\geq 28$ & $306(13.2)$ & $61(21.5)$ & $2.68(1.85,3.89)$ & $<0.0001$ \\
\hline p-trend & & & & $<0.0001$ \\
\hline \multicolumn{5}{|l|}{ Hysterectomy } \\
\hline No & 2129 (91.0) & $273(95.1)$ & 1.00 (referent) & \\
\hline Yes & $210(9.0)$ & $14(4.9)$ & $0.72(0.41,1.28)$ & 0.27 \\
\hline \multicolumn{5}{|l|}{ Appendectomy ${ }^{\dagger}$} \\
\hline No & $1458(80.2)$ & $166(81.8)$ & 1.00 (referent) & \\
\hline Yes & 359 (19.8) & $37(18.2)$ & $1.28(0.86,1.92)$ & 0.23 \\
\hline \multicolumn{5}{|l|}{ Tubal ligation } \\
\hline No & $1906(81.5)$ & $258(89.9)$ & 1.00 (referent) & \\
\hline Yes & 433 (18.5) & $29(10.1)$ & $0.65(0.43,0.99)$ & 0.05 \\
\hline \multicolumn{5}{|l|}{ Parity } \\
\hline Nulliparous & $421(18.0)$ & $114(39.7)$ & 1.00 (referent) & \\
\hline Parous & 1918 (82.0) & $173(60.3)$ & $0.56(0.40,0.79)$ & 0.0009 \\
\hline \multicolumn{5}{|l|}{ Parity } \\
\hline Nulliparous & $421(18.0)$ & $114(39.7)$ & 1.00 (referent) & \\
\hline 1 & 294 (12.6) & $46(16.0)$ & $0.79(0.49,1.26)$ & 0.33 \\
\hline 2 & 729 (31.2) & $56(19.5)$ & $0.43(0.25,0.76)$ & 0.003 \\
\hline$>2$ & 895 (38.3) & $71(24.7)$ & $0.46(0.20,1.07)$ & 0.07 \\
\hline$p$-trend & & & & 0.008 \\
\hline \multicolumn{5}{|l|}{ Breast fed } \\
\hline No & $1240(53.0)$ & $200(69.7)$ & 1.00 (referent) & \\
\hline Yes & 1099 (47.0) & $87(30.3)$ & $0.62(0.47,0.83)$ & 0.002 \\
\hline OC use & & & & \\
\hline
\end{tabular}




\begin{tabular}{|lcccc|}
\hline & $\begin{array}{c}\text { Controls } \\
\mathbf{n = 2 3 3 9} \\
\mathbf{N}(\%)\end{array}$ & $\begin{array}{c}\text { Cases } \\
\mathbf{n = 2 8 7} \\
\mathbf{N}(\%)\end{array}$ & $\begin{array}{c}\text { Adjusted* } \\
\text { OR (95\% CI) }\end{array}$ & p-value \\
\hline No & $920(39.3)$ & $120(41.8)$ & 1.00 (referent) & \\
Yes & $1419(60.7)$ & $167(58.2)$ & $0.80(0.61,1.06)$ & 0.11 \\
Family history of BRCA or OVCA & & & & \\
No & $2187(93.5)$ & $274(95.5)$ & 1.00 (referent) & \\
Yes & $152(6.5)$ & $13(4.5)$ & $0.72(0.40,1.29)$ & 0.27 \\
Personal history of BRCA & & & & \\
No & $2251(96.2)$ & $283(98.6)$ & $1.00($ referent $)$ & \\
Yes & $88(3.8)$ & $4(1.4)$ & $0.52(0.19,1.44)$ & 0.21 \\
\hline
\end{tabular}

\footnotetext{
* Adjusted for reference age, study center and phase, parity, breastfeeding, OC use, genital talc use, Jewish ethnicity, tubal ligation. ${ }^{\dagger}$ Information not available for phase 3 of the study.
} 
Table 2

GI tumors metastatic to the ovary operated on by a gynecologic oncologist

\begin{tabular}{|l|c|}
\hline & N (\%) \\
\hline All Cases & $26(100)$ \\
\hline Primary tumor & \\
Appendiceal & $8(30.8)$ \\
Colorectal & $8(30.8)$ \\
Gastric & $1(3.8)$ \\
Small bowel & $1(3.8)$ \\
Uncertain & $8(30.8)$ \\
Presence of Occult Appendiceal Pathology & \\
Suspected but not seen & $1(3.8)$ \\
Incidental carcinoid & $1(3.8)$ \\
Appendix unidentifiable & $1(3.8)$ \\
None & $23(88.5)$ \\
Presence of Signet-Ring Cell Morphology & \\
Yes & $9(34.6)$ \\
No & $17(65.4)$ \\
\hline
\end{tabular}


Table 3

Appendiceal pathology at the time of surgery for mucinous ovarian neoplasms

\begin{tabular}{|l|c|}
\hline & $\mathbf{N}(\%)$ \\
\hline All Cases & $170(100)$ \\
\hline Histology & \\
Borderline & $91(53.5)$ \\
Invasive & $79(46.5)$ \\
Appendectomy & \\
Yes & $72(42.4)$ \\
No & $98(57.6)$ \\
Presence of Appendiceal pathology & \\
Carcinoid tumor & $1(0.6)$ \\
Superficial metastases (grossly visible) & $3(1.8)$ \\
Isolated microscopic metastatic lesions & $0(0)$ \\
\hline
\end{tabular}




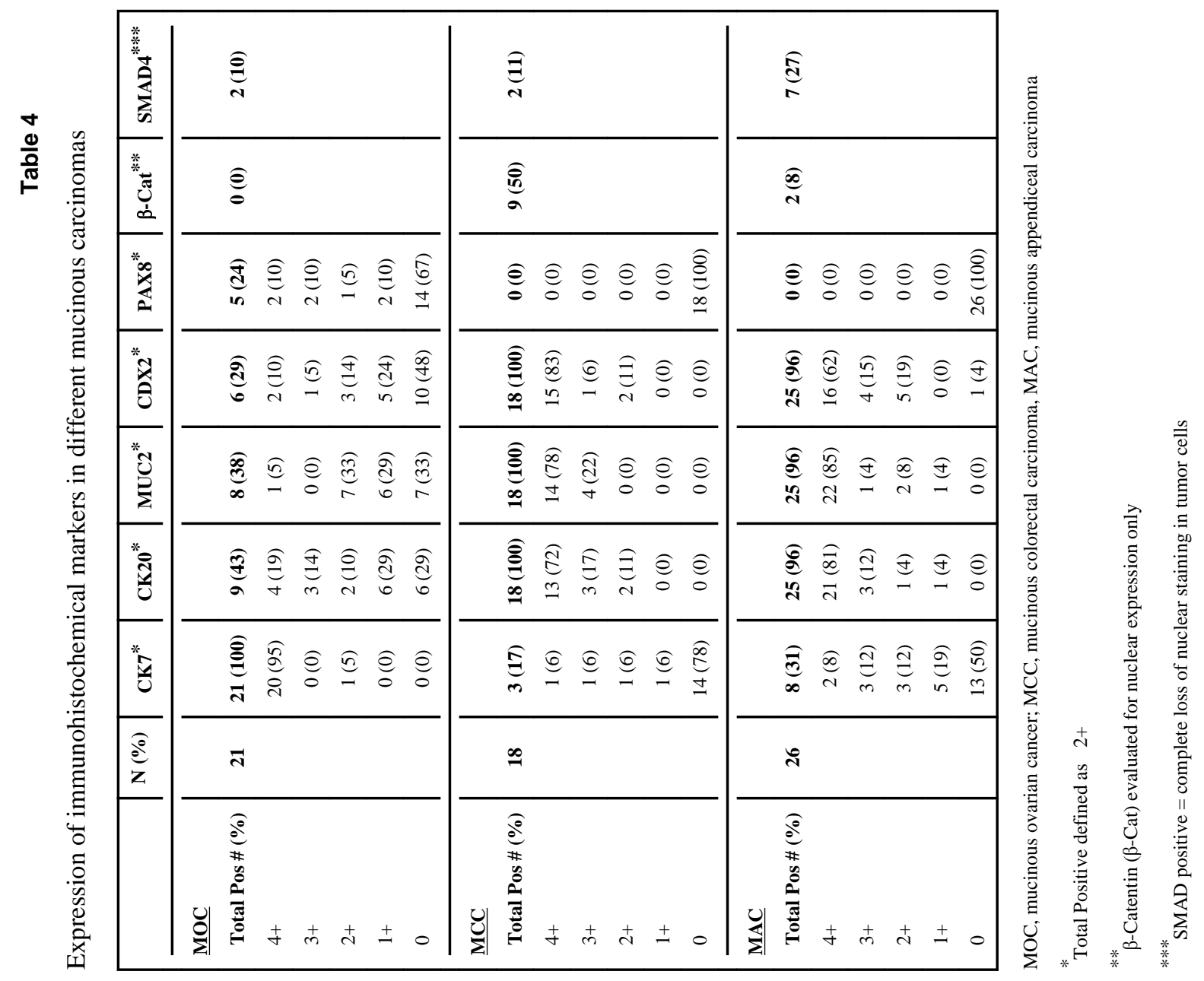

